\title{
AHP-Normal Cloud-Model-Based Method for Risk Assessment of Rockfall Hazards in Laoying Yan
}

\author{
Xin-Bao Gu ${ }^{1,2 *}$, Suai-Tao $\mathrm{Wu}^{1}$, Qi-Hong $\mathrm{Wu}^{3}$, Yun-Hua $\mathrm{Zhu}^{4}$ \\ ${ }^{1}$ School of Civil Engineering, Nanyang Institute of Technology, Nanyang, Henan,China \\ ${ }^{2}$ Guizhou Provincial Key Laboratory of Rock and Soil Mechanics and Engineering Safety, Guiyang, 550025, China \\ ${ }^{3}$ School of Architecture and Civil Engineering, Chengdu University, Chengdu, Sichuan, China \\ ${ }^{4}$ School of Civil Engineering, Neijiang Normal University, Neijiang, Sichuan,China
}

Received: 12 January 2021

Accepted: 24 March 2021

\begin{abstract}
The rockfall hazard is one of geological hazards in mountainous zone, its occurrence is complex, fuzzy and random. To assess the risk level of rockfall hazards in Laoying Yan accurately, AHP-Normal cloud model is introduced at first; secondly, the index weight coefficients are calculated by using AHP method, then the certainty degree of each index belonging to the corresponding cloud is obtained by using the norm cloud model. The final risk level of rockfall hazards is determined according to the synthetic certainty degree. The conclusions are drawn that accurate rate of risk estimation about rockfall hazards is very high, necessible measures should be taken to prevent possible occurrence of rockfall hazards.
\end{abstract}

Keywords: risk assessment, rockfall hazards, Laoying Yan, AHP-Normal cloud model

\section{Introduction}

The rockfall hazard is one of geological hazards in mountainous zone. The life and property safety of people near the town or residential zone is often threatened by the collapse of dangerous rock mass [1], for example, abrupt landslide [2] in Nanzhang county, Hubei province, China in January 20, 2017. The scale of fractured rock mass is about $3000 \mathrm{~m}^{3}$, the part buildings in a hotel are collapsed, and the death toll is twelve,

*e-mail: 15823405952@163.com direct economic loss arrives at more than 20 millions yuan. So the risk assessment of rockfall hazards has great significance in reality [3].

The risk assessment of the rockfall hazards has been investigated by many researchers [4]. The qualitative investigation on the assessment method is primary at the early stages. More and more mathematical models are applied to assess the risk level of rockfall hazards as deep investigations are performed. The hierarchical analytical method is used to analyze the stability of dangerous rock mass in Chongqing by Dong etc [5]. And then the norm grey theory is provided by $\mathrm{Li}$, etc [6] to assess the influential factor of dangerous rock formation. Variable fuzzy set theory is suggested by 
Wu, et al [7], and it is compared with other methods, the results demonstrate that variable fuzzy set theory has better applicability relative to other methods to assess risk level of rockfall under earthquake loading [8]. And then the probability index method [9], the method about information amount [10], logistic regression model [11] are respectively applied to assess the risk level in different zones, and the precision about three models is compared [12]. The hierarchy analytical synthetic index theory is provided by Wang, et al. [13] to assess the risk level of single hidden trouble point. The risk assessment of rockfall hazard area in highways is performed by Wang, et al. [14] using GIS based on superposition theory about regional influential factors; AHP-fuzzy synthetic assessment theory is suggested by Ye, et al. [15] to predict the stability of dangerous rock mass in combination with hierarchy analysis and fuzzy comprehensive evaluation method. Although the risk assessment is improved enormously because of the application of above methods, these methods still exists some limitations [16], for instance,their computational loads are great, and the correlation between assessment indices is not considered [17], and great complexity, fuzziness and randomness of rockfall hazards occurrence are ignored. The above shortcomings are solved successfully by using AHPNormal cloud theory. The inner relationship between fuzziness and randomness can not only be expressed [18], but also the conversion between qualitative concepts and quantitative characteristics can also be realized because of the application of AHP-Normal cloud model. Nowadays, the cloud model is widely used in many fields, it is applied to assess the risk level of rockfall hazards in Laoying Yan in the paper.

The paper is organized as follows: in Section 1, the engineering background in the study area is introduced at first. In Section 2, a new risk assessment method of rockfall hazards is introduced based on the cloud model and the AHP algorithm. In Section 3, the AHP-Normal cloud model is established about rockfall hazards in Laoying Yan, and the assessment results of the proposed cloud model are discussed. In Section 4, conclusions are drawn.

\section{Materials and Methods}

\section{Study Area}

Jiang Jin zone is located in the southwestern region in Chongqing province, China. And it was siting at the upper stream of Yangtze River, the end of three gorges reservoir area.The area arrives at 3200 square kilometers. Laoying Yan is lied in the Shuangxi village, Longhua town, Jiangjin zone. The village load XC98 goes through between the Longhua town and JiangJin zone, its topography is gentle. The survey area is plotted in Fig. 1. The geomorphology in the survey area belongs to denudation and erosion valley and hill, its terrain is high in the East and low in the West. Its highest point lies at the top of dangerous rock mass $\mathrm{W}_{1}$ in Laoying Yan, its elevation is $326.11 \mathrm{~m}$. The lowest point lies at the slope angle of ramps, its elevation is $142.21 \mathrm{~m}$, their relative elevation difference is $183.9 \mathrm{~m}$, the terrain is very steep, the slope angle is about $20^{\circ} \sim 45^{\circ}$, the local slope angle represents the upright states, it is shown in Figs 2 and 3. The stratigraphic lithology in the survey area are composed of four types:quaternary holocene colluvial soil, residual soil layers of slope, middle jurassic bright red mudstone and sandstone interbed. The strata is continual and stable in the survey area, the inclination angle of rock stratum is gentle. The altitude of rock stratum are between $65^{\circ} \angle 4^{\circ}$ and $113^{\circ} \angle 12^{\circ}$, there are not faults and fracture zones, the regional tectonic stability is good. But once the dangerous rock mass collapsed, the life and property safety of people will be seriously endangered, so it is very essential to assess the risk of rockfall hazards in Laoying Yan.

\section{The Risk Assessment of Rockfall Hazards}

The occurrence of rockfall hazards not only hindered the local traffic seriously, but also brought great loss for life and property safety of people. Consequently, it is very essential to analyze and assess the risk level of

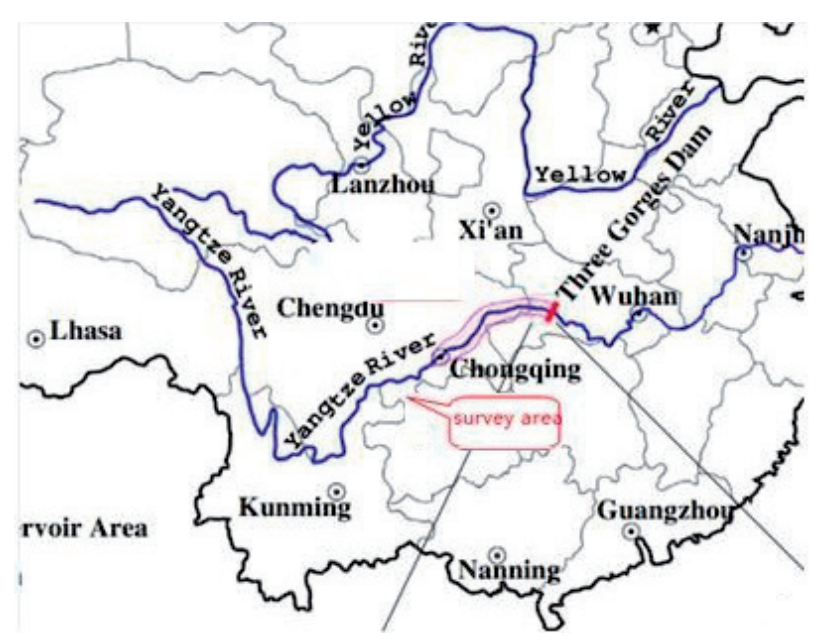

Fig. 1. The geographical location of the survey area.

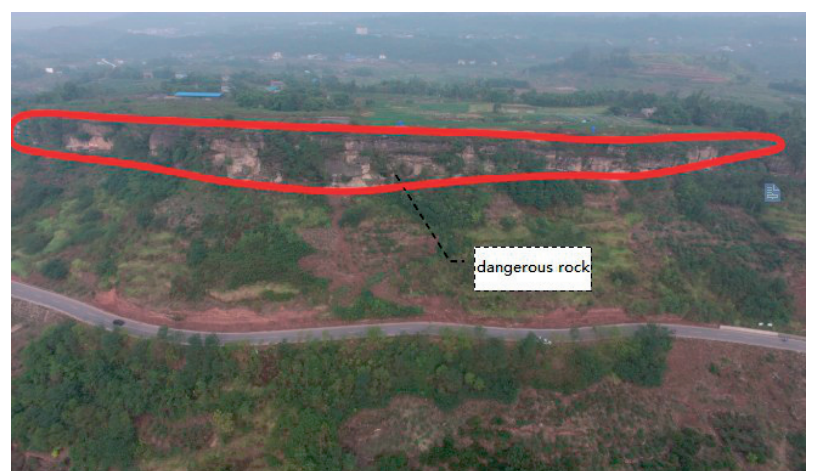

Fig. 2. The dangerous rock mass in Laoying Yan. 


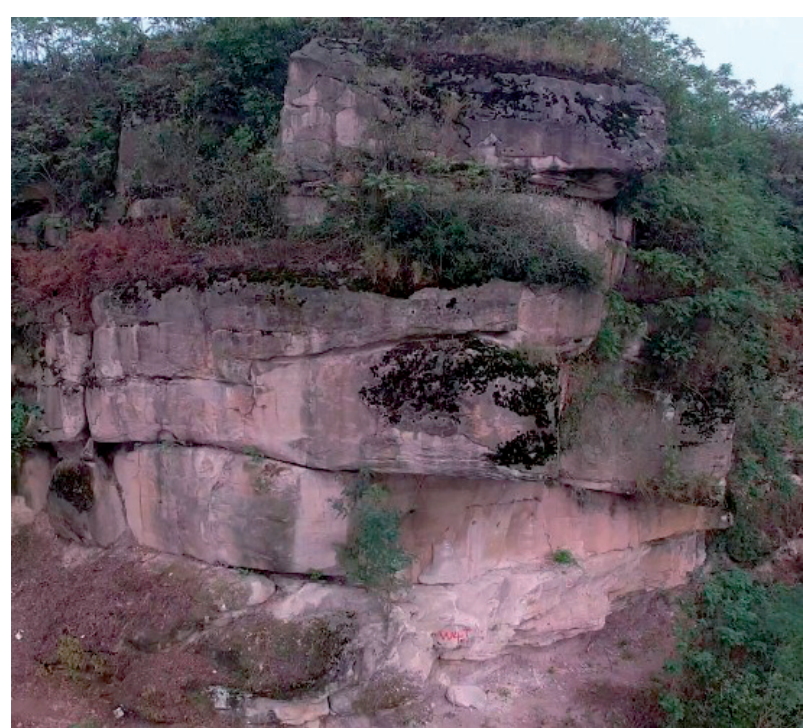

Fig. 3.The steel rock mass in Laoying Yan.

rockfall hazards in Laoying Yan to prevent from the occurrence of rockfall hazards.

A new risk assessment model of rockfall hazards is provided, which is based on AHP-Normal cloud theory, its process is plotted in Fig. 4.
Firstly,a complete assessment index systems are built up. Secondly, the weight coefficients of different assessment indices are calculated by using AHP method. Finally, the comprehensive certainty degree is determined based on normal cloud model, and then the risk level of rockfall hazards can be obtained.

\section{The Establishment of Index Systems}

Rockfall hazards are caused by many factors, these factors are very complicated. According to relevant investigations [19], they can be categorized as three types: topographic and geological condition $U_{1}$ (including the height of stiff cliff $U_{11}$, construction feature of still cliff $U_{12}$ and the geological structure of stiff cliff $U_{13}$ ). Geometry character of dangerous rock mass $U_{2}$ (including the scale of rockfall mass $U_{21}$, the inclination angle of main control plane $U_{22}$ and the through degree of main control plane $U_{23}$ ). Other factors $U_{3}$ (including the daily maximum rainfall $U_{31}$, weathering action $U_{32}$, the earthquake intensity $U_{33}$ and human engineering activity $U_{34}$ ); In the established evaluation system, indices $U_{11}, U_{21}, U_{22}, U_{23}$ and $U_{31}$ are quantitative indices, and the index values were obtained by the measured data in the projection. The rest indices are qualitative, and their values are determined by

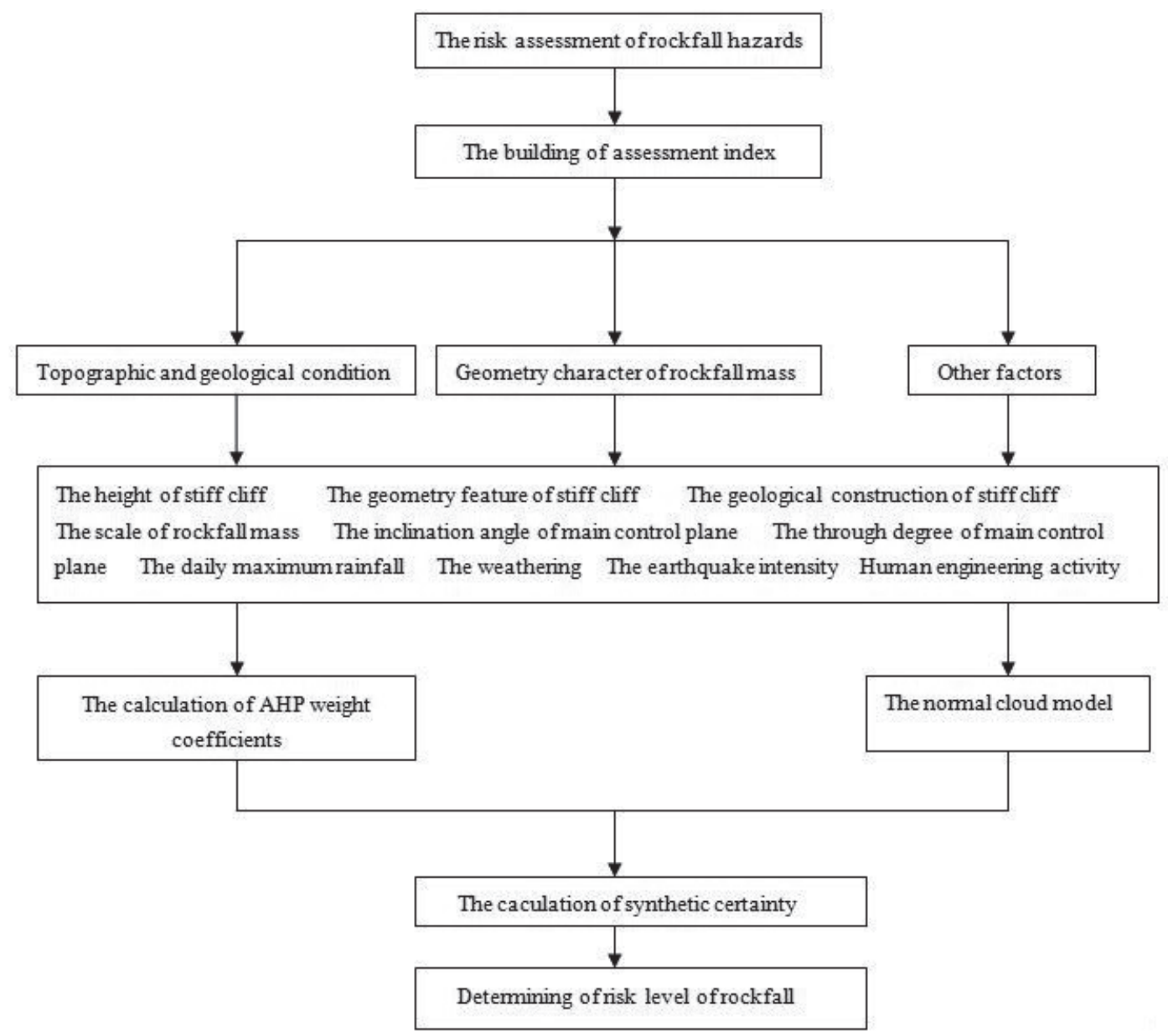

Fig. 4. The risk assessment process of rockfall hazards based on a AHP-Normal cloud model. 
Table 1. The standard classification of assessment index about rockfall hazards.

\begin{tabular}{|c|c|c|c|c|c|}
\hline \multirow{2}{*}{$\begin{array}{l}\text { Assessment } \\
\text { index }\end{array}$} & \multirow{2}{*}{ Code } & \multicolumn{4}{|c|}{ The risk level } \\
\hline & & I & II & III & IV \\
\hline The height of stiff cliff (m) & $U_{11}$ & $<15$ & {$[15$ 50] } & {$\left[\begin{array}{ll}50 & 100\end{array}\right]$} & $\geq 100$ \\
\hline Construction feature of still cliff & $U_{12}$ & $\begin{array}{c}\text { No weak structural } \\
\text { plane }\end{array}$ & $\begin{array}{l}\text { Inclined slope weak } \\
\text { structural plane }\end{array}$ & $\begin{array}{l}\text { Horizontal weak } \\
\text { structural plane }\end{array}$ & $\begin{array}{l}\text { Inclined out-slope weak } \\
\text { structural plane }\end{array}$ \\
\hline $\begin{array}{l}\text { The geological } \\
\text { structure of stiff cliff }\end{array}$ & $U_{13}$ & $\begin{array}{l}\text { Horizontal rock } \\
\text { stratum }\end{array}$ & Anticline rock stratum & $\begin{array}{l}\text { bedding rock } \\
\text { stratum }\end{array}$ & $\begin{array}{l}\text { Anticlinal nucleus or } \\
\text { fracture zone }\end{array}$ \\
\hline $\begin{array}{l}\text { The scale of rockfall mass } \\
\qquad\left(10^{4} \mathrm{~m}^{3}\right)\end{array}$ & $U_{21}$ & {$\left[\begin{array}{ll}0 & 1\end{array}\right]$} & {$\left[\begin{array}{ll}1 & 10\end{array}\right]$} & {$\left[\begin{array}{ll}10 & 100\end{array}\right]$} & $>100$ \\
\hline $\begin{array}{l}\text { The inclination angle of main } \\
\text { control plane }\left({ }^{0}\right)\end{array}$ & $U_{22}$ & {$[045)$} & {$[4560)$} & {$[6075)$} & {$\left[\begin{array}{ll}75 & 90\end{array}\right]$} \\
\hline $\begin{array}{l}\text { The through degree of of main } \\
\text { control plane }\end{array}$ & $U_{23}$ & {$\left[\begin{array}{ll}0 & 0.25\end{array}\right)$} & {$\left[\begin{array}{lll}0.25 & 0.5\end{array}\right)$} & {$\left[\begin{array}{lll}0.5 & 0.75)\end{array}\right.$} & {$\left[\begin{array}{lll}0.75 & 1\end{array}\right]$} \\
\hline The daily maximum rainfall (m) & $U_{31}$ & {$\left[\begin{array}{ll}0 & 10\end{array}\right)$} & {$\left[\begin{array}{ll}10 & 25\end{array}\right)$} & {$[2550)$} & $\geq 50$ \\
\hline Weathering action & $U_{32}$ & no weathering & Weak weathering & $\begin{array}{l}\text { Medium weather- } \\
\text { ing }\end{array}$ & Strong weathering \\
\hline $\begin{array}{l}\text { The earthquake } \\
\text { intensity }\end{array}$ & $U_{33}$ & $\leq \mathrm{V}$ & VI & VII & $\geq$ VIII \\
\hline Human engineering activity & $U_{34}$ & No influence & Weak influence & Medium influence & Strong influence \\
\hline
\end{tabular}

the expert investigation. In combination with rockfall hazard classification, the ten risk assessment indices were divided into four levels: low risk (I), medium risk (II), high risk (III), and higher risk (IV), as shown in Table 1.

To determine the risk level of rockfall hazards, the degree of membership about five quantitative indices can be shown in Table 2 as follows:

\section{The Height of Still Sliff $\left(U_{11}\right)$}

According to the geological survey, the development and collapse of dangerous rock often happens in stiff and high slope area. The stress redistribution is aroused by the still cliff. The tension stress concentration formed at the shoulder of cliff. The shear stress formed at the foot of cliff.

Table 2. The degree of membership about quantitative indices.

\begin{tabular}{|c|c|c|c|c|}
\hline$U_{12}$ & $\begin{array}{c}\text { No weak structural } \\
\text { plane }\end{array}$ & $\begin{array}{l}\text { Inclined slope weak } \\
\text { structural plane }\end{array}$ & $\begin{array}{l}\text { Horizontal weak struc- } \\
\text { tural plane }\end{array}$ & $\begin{array}{l}\text { Inclined out-slope weak } \\
\text { structural plane }\end{array}$ \\
\hline \multirow{2}{*}{ The degree of membership } & $\mathrm{I}=1, \mathrm{II}=0$ & $\mathrm{I}=0, \mathrm{II}=1$ & $\mathrm{I}=0, \mathrm{II}=0$ & $\mathrm{I}=0, \mathrm{II}=0$ \\
\hline & $\mathrm{III}=0, \mathrm{IV}=0$ & $\mathrm{III}=0, \mathrm{IV}=0$ & $\mathrm{III}=1, \mathrm{IV}=0$ & $\mathrm{III}=0, \mathrm{IV}=1$ \\
\hline$U_{13}$ & $\begin{array}{l}\text { Horizontal rock } \\
\text { stratum }\end{array}$ & Anticline rock stratum & Bedding rock stratum & $\begin{array}{l}\text { Anticlinal nucleus or } \\
\text { fracture zone }\end{array}$ \\
\hline \multirow{2}{*}{ The degree of membership } & $\mathrm{I}=1, \mathrm{II}=0$ & $\mathrm{I}=0, \mathrm{II}=1$ & $\mathrm{I}=0, \mathrm{II}=0$ & $\mathrm{I}=0, \mathrm{II}=0$ \\
\hline & $\mathrm{III}=0, \mathrm{IV}=0$ & $\mathrm{III}=0, \mathrm{IV}=0$ & $\mathrm{III}=1, \mathrm{IV}=0$ & $\mathrm{III}=0, \mathrm{IV}=1$ \\
\hline$U_{32}$ & no weathering & Weak weathering & Medium weathering & Strong weathering \\
\hline \multirow{2}{*}{ The degree of membership } & $\mathrm{I}=1, \mathrm{II}=0$ & $\mathrm{I}=0, \mathrm{II}=1$ & $\mathrm{I}=0, \mathrm{II}=0$ & $\mathrm{I}=0, \mathrm{II}=0$ \\
\hline & $\mathrm{III}=0, \mathrm{IV}=0$ & $\mathrm{III}=0, \mathrm{IV}=0$ & $\mathrm{III}=1, \mathrm{IV}=0$ & $\mathrm{III}=0, \mathrm{IV}=1$ \\
\hline$U_{33}$ & $\leq \mathrm{V}$ & VI & VII & $\geq$ VIII \\
\hline \multirow{2}{*}{ The degree of membership } & $\mathrm{I}=1, \mathrm{II}=0$ & $\mathrm{I}=0, \mathrm{II}=1$ & $\mathrm{I}=0, \mathrm{II}=0$ & $\mathrm{I}=0, \mathrm{II}=0$ \\
\hline & $\mathrm{III}=0, \mathrm{IV}=0$ & $\mathrm{III}=0, \mathrm{IV}=0$ & $\mathrm{III}=1, \mathrm{IV}=0$ & $\mathrm{III}=0, \mathrm{IV}=1$ \\
\hline$U_{34}$ & No influence & Weak influence & Medium influence & Strong influence \\
\hline \multirow{2}{*}{ The degree of membership } & $\mathrm{I}=1, \mathrm{II}=0$ & $\mathrm{I}=0, \mathrm{II}=1$ & $\mathrm{I}=0, \mathrm{II}=0$ & $\mathrm{I}=0, \mathrm{II}=0$ \\
\hline & $\mathrm{III}=0, \mathrm{IV}=0$ & $\mathrm{III}=0, \mathrm{IV}=0$ & $\mathrm{III}=1, \mathrm{IV}=0$ & $\mathrm{III}=0, \mathrm{IV}=1$ \\
\hline
\end{tabular}




\section{The Construction Feature of Still Cliff $\left(U_{12}\right)$}

The development of joint and fissure in the stiff cliff of rock mass and the existence of air surface result in the collapse. The weak interlayer under the gravity of upper rock mass leads to the occurrence of plastic deformation, tension fracture will take place in the upper of rock mass, final collapse will form.

\section{The Geological Structure of Stiff Cliff $\left(U_{13}\right)$}

The different geological structure have different influences on the development of collapse mass around the rock: (1) anticlinal nucleus: the fracture is inclined to take place in the rock stratum at the maximum curvature, plenty of tension fissures will form as the action of rock stratum, so the collapse mass is formed; (2) because rock mass become very fragile in the fault zone, this construction is benefit for the infiltration of groundwater, rock mass will be softened, so the collapse mass will be formed easily; (3) the landslide collapse will happen easily when the rock stratum at two flanks of fold represents monoclinic state, and the inclinations of rock stratum are parallel to ones of landslides, the slip surface is often the surface of rock stratum, dislocation plane or weak interlayer.

\section{The Scale of Dangerous Rock Mass $\left(U_{21}\right)$}

When the scale of rockfall mass becomes greater, the normal stress and shear stress in the corresponding main control plane becomes greater, and the collapse mass lose the stability easily, so the degree of harm become greater.

The Through Degree $\left(U_{23}\right)$ and Inclination Angle $\left(U_{22}\right)$ of Main Control Plane

The structure feature of collapse mass has important control action on the stability. When the main control plane of collapse mass is cut deeper, the pressure action of fissure water become bigger, so the collapse mass will become unstable more and more. The magnitude of collapse mass in the main control plane will influence the unstable mode of collapse mass, so the through degree and inclination angle of of main control plane are selected as the risk indices of collapse mass.

$$
\text { The Influences of Rainfall }\left(U_{31}\right)
$$

The large static and dynamic crevice water pressure can be formed easily in the rainstorm season, and the rock at the base of collapse mass will be softened by the infiltrated fissure water, the strengthen parameters of rock mass are reduced obviously, this will aggregate rapid deformation of collapse mass, even result in the destroy,so the rainfall is selected as a risk index.
The Weathering Action $\left(U_{32}\right)$

The rock mass in the stiff cliff become more and more fragile and loose because of the weathering action, it will result in the further development of fissures, so the weathering action is selected as a risk index.

$$
\text { The Earthquake Intensity }\left(U_{33}\right)
$$

The influential sizes of earthquake force on collapse mass in the stiff cliff are related with the weight of collapse mass and influential coefficients of earthquake force. When the earthquake acceleration exceeds critical acceleration, the crack of main control plane about the collapse mass will enlarge. The extended length is correlate with the energy and duration time of earthquake. When energy and duration time of collapse mass become bigger, the stability of collapse mass becomes the worse.

\section{The Human Engineering Activity $\left(U_{34}\right)$}

The human engineering activity is an important factor resulted in the formation and development of collapse mass. For example, manual blasting, unreasonable excavation and underground mining, etc, will influence the stability of collapse mass about dangerous rock. So the human engineering activity is selected as a risk index.

\section{The AHP Theory}

\section{The Construction of Evaluation Hierarchy Diagram}

Because 10 risk indices are selected in the paper, and their influences on the collapse of dangerous rock mass are non-linear, AHP method is adopted to estimate the weight coefficients of different indices. The collapse of dangerous rock mass are selected as target layer at first. Secondly, topographic and geological condition $U_{1}$ Geometry character of collapse mass $U_{2}$ and Other factors $U_{3}$ are selected as criterion layer. Thirdly, 10 risk indices are selected as sub-criterion layer. Their relations are plotted in Fig. 5 as follows:

\section{The Construction of Weight Coefficients about Different Indices}

The consistent checking formula is expressed as follows:

$$
\mathrm{CR}=\frac{\mathrm{CI}}{\mathrm{RI}}
$$

...where, $\mathrm{CR}$ is the random consistent ratio of judgement matrix; $\mathrm{CI}$ is the consistent index of judgement matrix. When $\mathrm{CR}<0.1$, it means that judgement matrix has good consistency, the distribution of weight coefficients is rational, otherwise the judgement matrix need be 


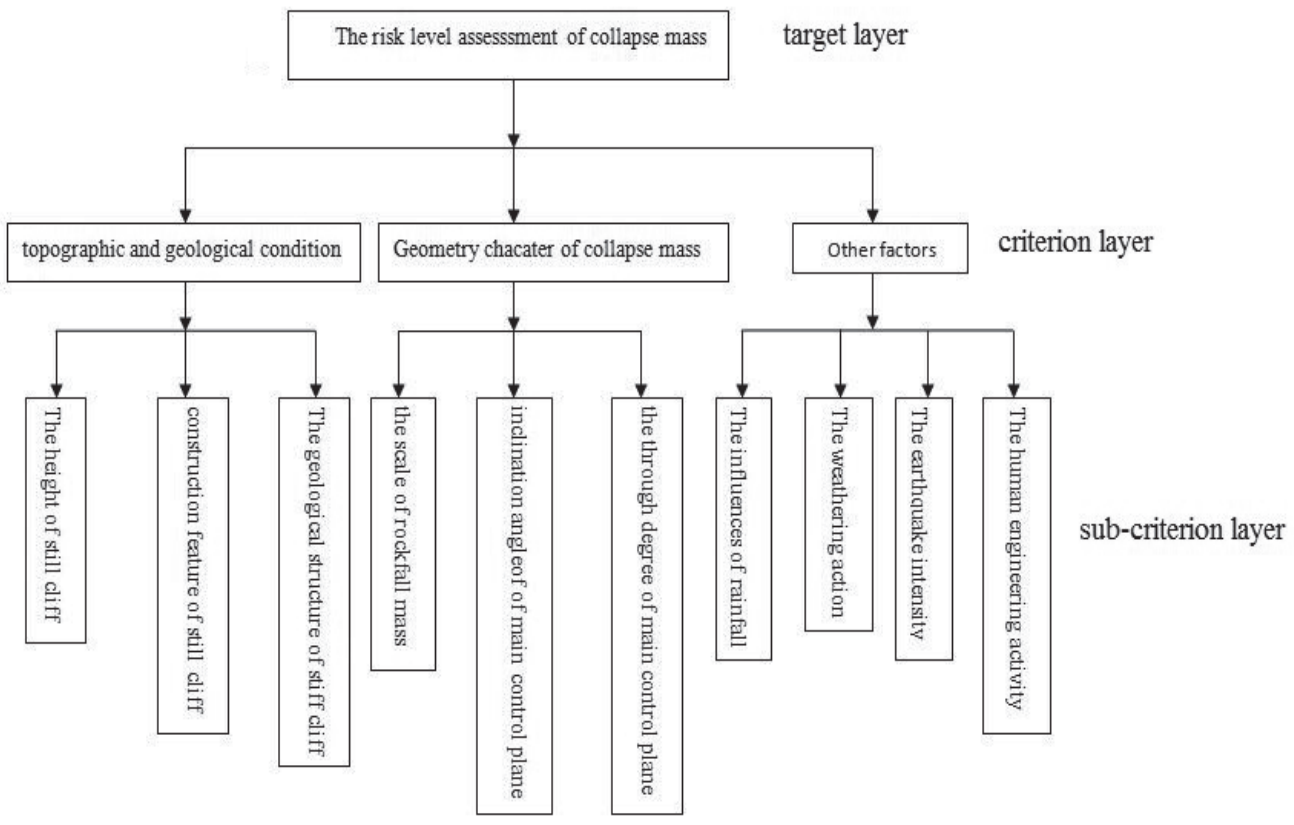

Fig. 5. The evaluation hierarchy diagram.

adjusted until it meets with the consistency [20]. CI can be expressed as follows:

$$
\mathrm{CI}=\frac{\lambda_{\max }-\mathrm{n}}{\mathrm{n}-1}
$$

...where, $\lambda_{\max }$ is the maximum characteristic root; $\mathrm{n}$ is the order number of judgement matrix; RI can be obtained in Table 3 for the low-order judgement matrix.

\section{The Classification of the Assessment Index}

The specific classification standards about the assessment index are shown in Table 1 and 2.

\section{The Normal Cloud Theory}

The cloud model theory is constructed on the idea of fuzzy sets theory [21] and probability concepts [22]. The cloud is defined as an uncertain transformation between some qualitative concepts and quantitative ones by using language value to react to uncertainty of knowledge concept for things or person in nature: the randomness and fuzziness. It constitutes the mapping between qualitative concepts and quantitative ones [23].

Let $U$ be a quantitative universe including exact values, and $M$ be the qualitative concept connected with $U$. If the qualitative value $x$ belongs to $U$, and $x$ is a random implementation by using the qualitative concept
$M$. The certainty degree $\mu(x) \in[0,1]$ of $x$ relative to qualitative concept $M$ is the random variable with steady tendency. When it can be expressed as:

$$
\mu: U \rightarrow[0,1] \quad \forall x \in U \quad x \rightarrow \mu(x)
$$

...where, the distribution of $x$ in qualitative domain $U$ is called as the cloud, and every $x$ is called as a cloud droplet, which is a tool as a quantitative meaning to describe a qualitative concept.

The digital characteristics of cloud is defined as the representative of the whole about the concept of cloud based on the normal cloud and membership function distributions [24]. The distribution of $x$ can be determined by three numerical eigenvalues $\left(E_{x}, E_{N}, H_{e}\right) ; E_{x}$ is an expectation value in the universe of discourse and the best characterization of a qualitative concept [25]. $E_{n}$ is the entropy of $E_{r}$, it represents variation range of a cloud droplet in the distribution; $H_{e}$ represents the measure of uncertain degree for entropy, namely, it is the entropy of entropy. Their eigenvalue in the normal cloud distribution can be shown in Fig. 6.

The transformation process from qualification to quantification is called as the positive cloud generator; On the contrary, it is called as the negative cloud generator [26]. Only the forward cloud generator in

Table 3. The consistent index value.

\begin{tabular}{|c|c|c|c|c|c|c|c|c|c|c|c|c|}
\hline $\mathrm{n}$ & 1 & 2 & 3 & 4 & 5 & 6 & 7 & 8 & 9 & 10 & 11 & 12 \\
\hline $\mathrm{RI}$ & 0 & 0 & 0.58 & 0.9 & 1.12 & 1.24 & 1.32 & 1.14 & 1.45 & 1.49 & 1.52 & 1.54 \\
\hline
\end{tabular}




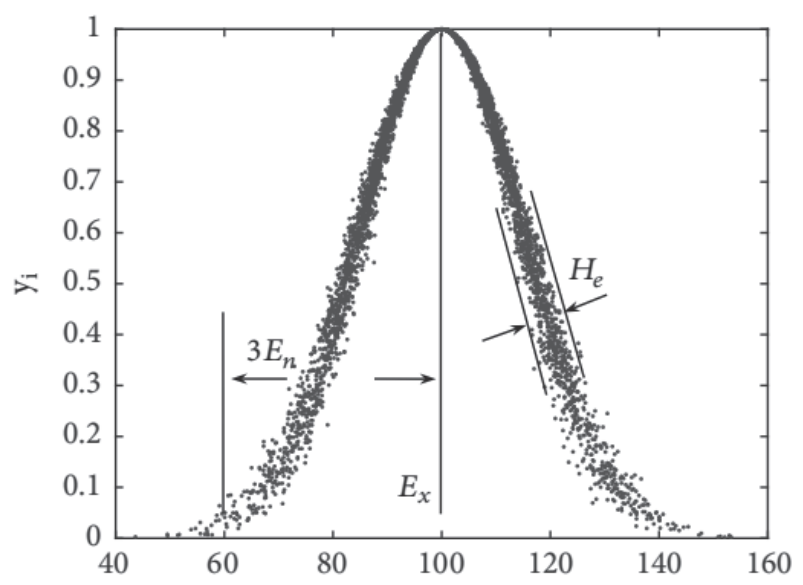

Fig. 6. The sketch map about the eigenvalue of cloud.

the paper is used, the backward cloud generator is omitted. Its transformation process is listed as follows: at first, the suitable cloud droplet is generated by using $C G \sim N^{3}\left(E_{x}, E_{N}, H_{e}\right)$, the production process of cloud drops represents the uncertainty of conversion between qualitative concept and quantitative values. Then $n$ cloud droplets are composed of cloud, so the qualitative concept is transformed as quantitative expression by using the uncertainty of cloud model, its process is shown in Fig. 7.

Its specific algorithm in Fig. 7 is listed as follows:

(1) Expectation $E_{n}$ and the standard deviation $H_{e}$ are respectively calculated;

(2) The normal random number $E_{n}{ }^{*}$ is generated according to the characteristic value $\left(E_{x}, E_{N}, H_{e}\right)$ of cloud, its expected value is $E_{n}$, and the standard deviation is $H_{e}$.

(3) A normal random number $x_{i}$ is generated, its expected value is $E_{x}$, and the standard deviation is $E_{n} ; x_{i}$ represents a quantitative value of a qualitative concept.

(4) The certainty degree $\mu$ of the qualitative concept $C$ is expressed according to procedure (1), (2) and (3).

\section{Results and Discussion}

\section{The Establishment of Risk Assessment Model}

Based on the AHP theory, according to Eqs. (1) and (2), the weight coefficients of each assessment index can be shown in Table 4 as follows:

To establish the normal cloud model, ten assessment indices in Table 1 are selected; These assessment indices are all forward assessment indices. When the

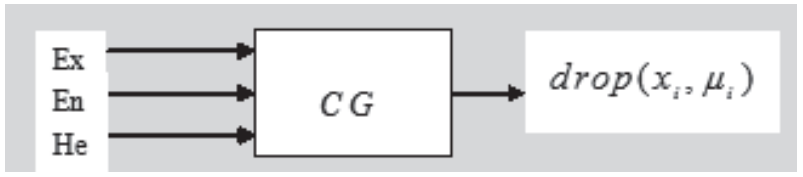

Fig. 7. The forward cloud generator. magnitude of these indices increases, the risk level of rockfall hazards becomes higher, these indices are defined as forward assessment index, otherwise, they are defined as negative index. In total, ten dangerous rock masses are selected as the assessment object. Their assessment indices are shown in Table 5.

To react the randomness and fuzziness, the risk assessment model about rockfall hazards is established, its assessment procedure is shown as follows:

(1) The index and evaluation sets are respectively set up to assess the risk level of rockfall hazards in Laoying Yan at first. In the paper, the datum in Table 5 is regarded as the index sets $U=\left\{u_{1}, u_{2}, \ldots, u_{n}\right\}$; Table 1 and 2 are evaluation sets $V=\left\{v_{1}, v_{2}, \ldots, v_{n}\right\}$.

(2) The fuzzy matrix M is established.The upper and lower boundary of index $j$ corresponding to index $i$ are respectively $x_{l}$ and $x_{n}$, then the qualitative concept $E_{x}$ of index $j$ 's level can be depicted as:

$$
E_{x}=\left(x_{l}+x_{u}\right) / 2
$$

Entropy has certain fuzziness for the risk assesment of rockfall hazards, so it is assumed as:

$$
E_{n}=\frac{\left(x_{u}-x_{l}\right)}{6}
$$

And the hyperentropy $H_{e}$ is a constant which reacts the dispersion degree of the cloud model. Where, the hyperentropy $H_{e}$ is set as 0.01 .

Apart from that, if a variable has only a single boundary, like $\left[-\infty, x_{u}\right]$ or $\left[x_{l},+\infty\right]$, its default boundary parameters can be determined by the value of the upper or lower bounds as follows:

$$
\begin{gathered}
E_{x}=1.5 x_{l} \\
E_{n}=\frac{E_{x}}{6}
\end{gathered}
$$

(3) The final mean degree of membership $T_{i j}$ is determined according to the assessment indices of rockfall hazards.

$$
T_{i j}=\frac{\sum_{i=1}^{n} t_{i j}^{m}}{N}
$$

...where, $t_{i j}{ }^{m}$ is the value that generated from the forward generator in $m$ th time; $N$ is calculative time.

(4) The comprehensive certainty degree of the risk grades about rockfall hazards can be depicted as:

$$
P_{j}(n)=\sum_{i} \omega_{i} \cdot M_{i j}
$$


Table 4. The weight coefficients of each index.

\begin{tabular}{|c|c|c|c|c|c|c|c|c|c|c|}
\hline Index & $\mathrm{U}_{11}$ & $\mathrm{U}_{12}$ & $\mathrm{U}_{13}$ & $\mathrm{U}_{21}$ & $\mathrm{U}_{22}$ & $\mathrm{U}_{23}$ & $\mathrm{U}_{31}$ & $\mathrm{U}_{32}$ & $\mathrm{U}_{33}$ & $\mathrm{U}_{34}$ \\
\hline Weight coefficients & 0.168 & 0.092 & 0.051 & 0.08 & 0.146 & 0.266 & 0.083 & 0.023 & 0.035 & 0.055 \\
\hline
\end{tabular}

Table 5. The data about dangerous rock mass to assess.

\begin{tabular}{|c|c|c|c|c|c|c|c|c|c|c|}
\hline Assessment index & $\mathrm{U}_{11}$ & $\mathrm{U}_{12}$ & $\mathrm{U}_{13}$ & $\mathrm{U}_{21}$ & $\mathrm{U}_{22}$ & $\mathrm{U}_{23}$ & $\mathrm{U}_{31}$ & $\mathrm{U}_{32}$ & $\mathrm{U}_{33}$ & $\mathrm{U}_{34}$ \\
\hline $\begin{array}{l}\text { Dangerous rock } \\
\text { mass } \mathrm{W}_{1} \\
\end{array}$ & 98 & $\begin{array}{c}\text { Inclined slope weak } \\
\text { structural plane }\end{array}$ & $\begin{array}{c}\text { Anticline rock } \\
\text { stratum }\end{array}$ & 16.3 & 65 & 0.61 & 231.1 & $\begin{array}{c}\text { Medium } \\
\text { weathering }\end{array}$ & VI & $\begin{array}{c}\text { Strong } \\
\text { influence }\end{array}$ \\
\hline $\begin{array}{c}\text { Dangerous rock } \\
\text { mass } \mathrm{W}_{2}\end{array}$ & 100 & $\begin{array}{c}\text { Inclined slope weak } \\
\text { structural plane }\end{array}$ & $\begin{array}{c}\text { Anticline rock } \\
\text { stratum }\end{array}$ & 3.8 & 65 & 0.69 & 231.1 & $\begin{array}{c}\text { Medium } \\
\text { weathering }\end{array}$ & VI & $\begin{array}{c}\text { Strong } \\
\text { influence }\end{array}$ \\
\hline $\begin{array}{c}\text { Dangerous rock } \\
\text { mass } \mathrm{W}_{3} \\
\end{array}$ & 98 & $\begin{array}{c}\text { Inclined slope weak } \\
\text { structural plane }\end{array}$ & $\begin{array}{c}\text { Anticline rock } \\
\text { stratum }\end{array}$ & 10 & 62 & 0.72 & 231.1 & $\begin{array}{c}\text { Medium } \\
\text { weathering }\end{array}$ & VI & $\begin{array}{c}\text { Strong } \\
\text { influence }\end{array}$ \\
\hline $\begin{array}{c}\text { Dangerous rock } \\
\text { mass } \mathrm{W}_{4} \\
\end{array}$ & 72 & $\begin{array}{c}\text { Horizontal weak } \\
\text { structural plane }\end{array}$ & $\begin{array}{l}\text { bedding rock } \\
\text { stratum }\end{array}$ & 4.75 & 84 & 0.57 & 231.1 & $\begin{array}{c}\text { Medium } \\
\text { weathering }\end{array}$ & VI & $\begin{array}{c}\text { Strong } \\
\text { influence }\end{array}$ \\
\hline $\begin{array}{c}\text { Dangerous rock } \\
\text { mass } \mathrm{W}_{5} \\
\end{array}$ & 81 & $\begin{array}{c}\text { Horizontal weak } \\
\text { structural plane }\end{array}$ & $\begin{array}{l}\text { Bedding rock } \\
\text { stratum }\end{array}$ & 9.3 & 86 & 0.63 & 231.1 & $\begin{array}{c}\text { Medium } \\
\text { weathering }\end{array}$ & VI & $\begin{array}{c}\text { Strong } \\
\text { influence }\end{array}$ \\
\hline $\begin{array}{c}\text { Dangerous rock } \\
\text { mass } W_{6} \\
\end{array}$ & 45.9 & $\begin{array}{c}\text { Horizontal weak } \\
\text { structural plane }\end{array}$ & $\begin{array}{c}\text { Bedding rock } \\
\text { stratum }\end{array}$ & 1.14 & 74 & 0.70 & 231.1 & $\begin{array}{c}\text { Strong } \\
\text { weathering }\end{array}$ & VI & $\begin{array}{c}\text { Strong } \\
\text { influence }\end{array}$ \\
\hline $\begin{array}{l}\text { Dangerous rock } \\
\text { mass } W_{7} \\
\end{array}$ & 64.8 & $\begin{array}{c}\text { Inclined slope weak } \\
\text { structural plane }\end{array}$ & $\begin{array}{c}\text { Bedding rock } \\
\text { stratum }\end{array}$ & 2.75 & 78 & 0.65 & 231.1 & $\begin{array}{c}\text { Strong } \\
\text { weathering }\end{array}$ & VI & $\begin{array}{c}\text { Strong } \\
\text { influence }\end{array}$ \\
\hline $\begin{array}{c}\text { Dangerous rock } \\
\text { mass } W_{8} \\
\end{array}$ & 53.4 & $\begin{array}{c}\text { Inclined slope weak } \\
\text { structural plane }\end{array}$ & $\begin{array}{l}\text { Bedding rock } \\
\text { stratum }\end{array}$ & 3.10 & 76 & 0.66 & 231.1 & $\begin{array}{c}\text { Medium } \\
\text { weathering }\end{array}$ & VI & $\begin{array}{c}\text { Strong } \\
\text { influence }\end{array}$ \\
\hline $\begin{array}{c}\text { Dangerous rock } \\
\text { mass } \mathrm{W}_{9}\end{array}$ & 29.1 & $\begin{array}{l}\text { Horizontal weak } \\
\text { structural plane }\end{array}$ & $\begin{array}{l}\text { Bedding rock } \\
\text { stratum }\end{array}$ & 2.33 & 79 & 0.65 & 231.1 & $\begin{array}{c}\text { Strong } \\
\text { weathering }\end{array}$ & VI & $\begin{array}{l}\text { Medium } \\
\text { influence }\end{array}$ \\
\hline $\begin{array}{c}\text { Dangerous rock } \\
\text { mass } \mathrm{W}_{10}\end{array}$ & 44.7 & $\begin{array}{l}\text { Horizontal weak } \\
\text { structural plane }\end{array}$ & $\begin{array}{l}\text { Bedding rock } \\
\text { stratum }\end{array}$ & 7.72 & 80 & 0.63 & 231.1 & $\begin{array}{c}\text { Strong } \\
\text { weathering }\end{array}$ & VI & $\begin{array}{l}\text { Medium } \\
\text { influence }\end{array}$ \\
\hline
\end{tabular}

...where, $P_{j}(n)$ is the comprehensive certainty degree of corresponding level $j$ of the dangerous rock mass $n ; \omega_{i}$ is the weight coefficient of $i t h$ assessment index of the $n t h$ dangerous rock mass. And $M_{i j}$ is the $j t h$ level's average certainty degree of the $i t h$ assessment index.

Finally, the risk assessment grade of the dangerous rock mass $n$ can be obtained as follows:

$$
L=\max \left(P_{1}, P_{2}, P_{3}, P_{4}\right)
$$

According to Table 1, and in combination with Eqs (4), (5), (6) and (7), the classification standard of normal cloud about rockfall hazards can be depicted in Table 6 .
The risk level of rockfall hazards is determined by the maximum synthetic certainty degree, and the distributions of the certainty degrees about each evaluation index in the four risk levels are depicted in Fig. 8. In Fig. 8, the abscissa is the value of each assessment index, and the ordinate is the corresponding value of the certainty degree.

\section{Risk Level Assessment}

In order to assess the reliability of the cloud model, the investigation results and AHP-Fuzzy methods

Table 6. The classification standard of normal cloud about rockfall hazards.

\begin{tabular}{|c|c|c|c|c|}
\hline \multirow{2}{*}{ Assessment index } & \multicolumn{4}{|c|}{ The risk assessment of rockfall hazards } \\
\cline { 2 - 5 } & $\mathrm{I}$ & $\mathrm{II}$ & $\mathrm{III}$ & $(150,25,0.01)$ \\
\hline $\mathrm{U}_{11}$ & $(7.5,2.5,0.01)$ & $(32.5,5.833,0.01)$ & $(75,8.333,0.01)$ & $(150,25,0.01)$ \\
\hline $\mathrm{U}_{21}$ & $(0.5,0.167,0.01)$ & $(5.5,1.5,0.01)$ & $(55,15,0.01)$ & $(82.5,2.5,0.01)$ \\
\hline $\mathrm{U}_{22}$ & $(22.5,7.5,0.01)$ & $(52.5,2.5,0.01)$ & $(67.5,2.5,0.01)$ & $(0.875,0.042,0.01)$ \\
\hline $\mathrm{U}_{23}$ & $(0.125,0.042,0.01)$ & $(0.375,0.042,0.01)$ & $(0.625,0.042,0.01)$ & $(75,12.5,0.01)$ \\
\hline $\mathrm{U}_{31}$ & $(5,1.667,0.01)$ & $(17.5,2.5,0.01)$ & $(37.5,4.167,0.01)$ & \\
\hline
\end{tabular}




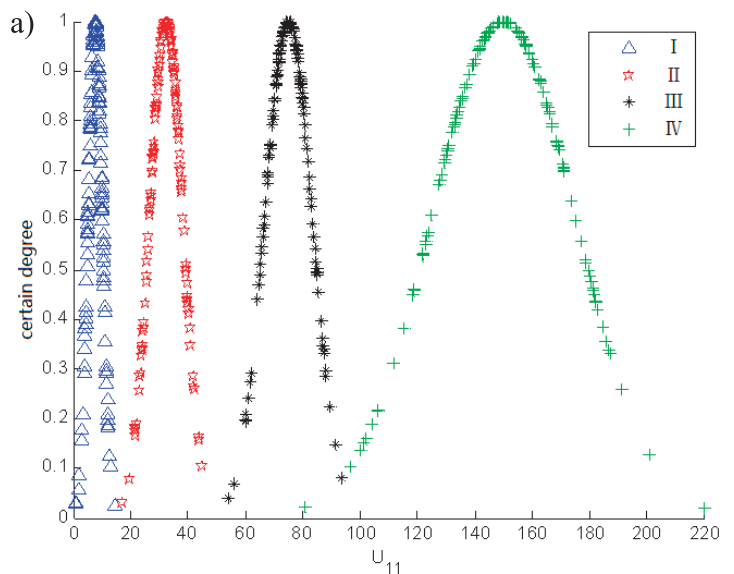

c)

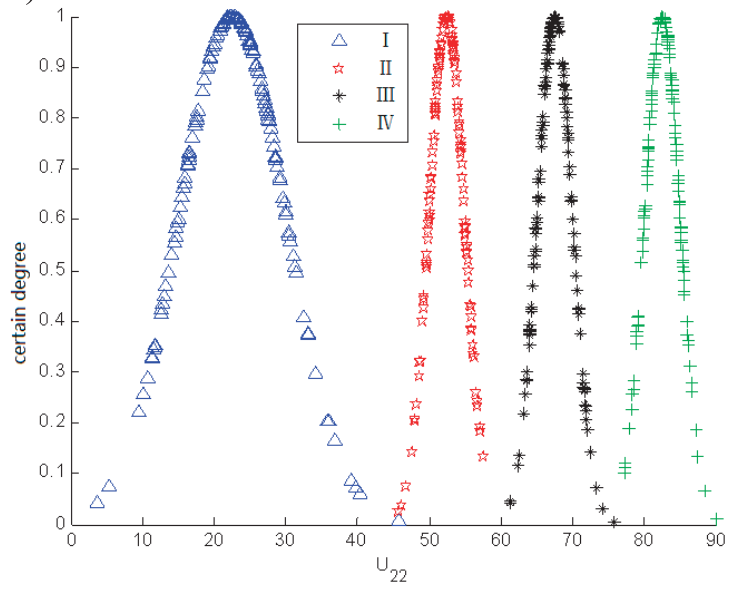

b)

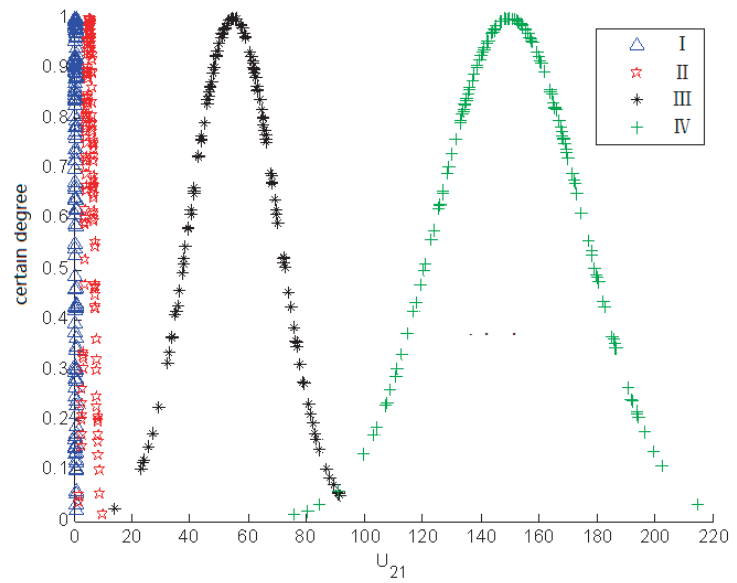

d)

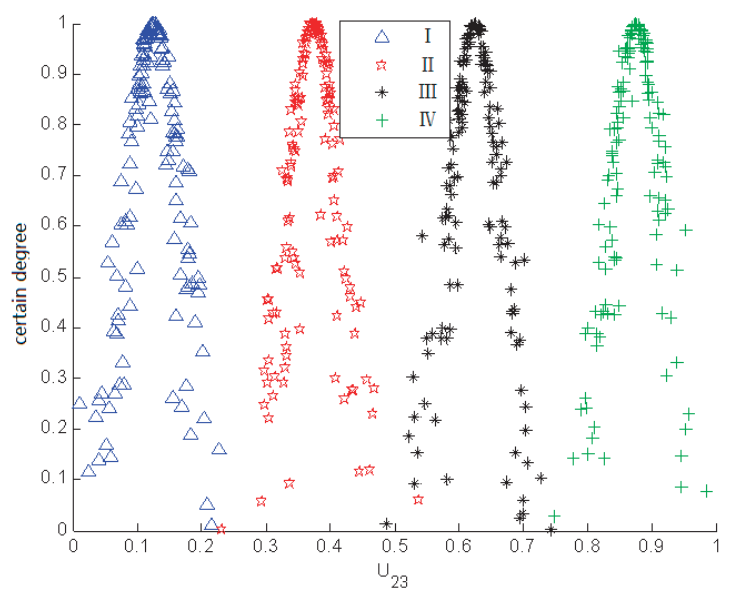

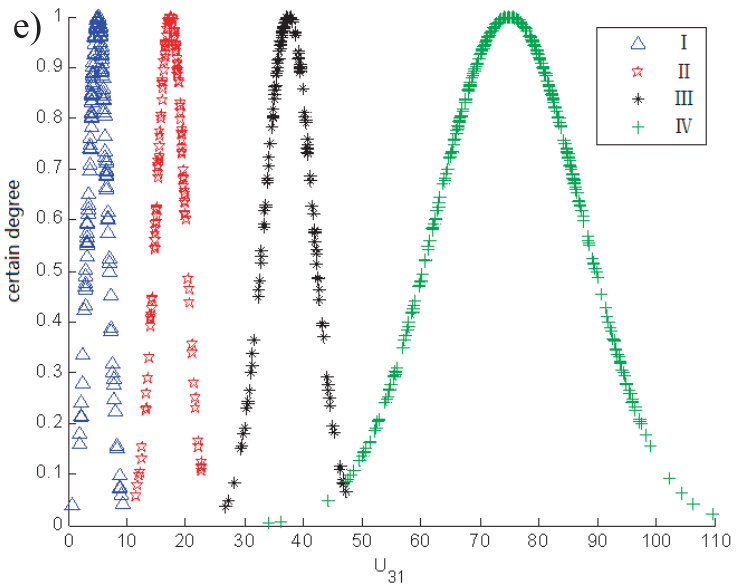

Fig. 8. Cloud of each assessment index generated by the forward cloud generator: a) The height of cliff stiff $U_{11}$, b) The scale of dangerous rock mass $U_{21}$, c)Inclination angle of of main control plane $U_{22}, d$ ) The through degree $U_{23}$, f) rainfall $U_{31}$.

are compared in this paper [27]. The evaluation results calculated by different methods are shown in Table 7.

It can be found from Table 7 that the rest dangerous rock masses all belong to level III except $\mathrm{W}_{2}$ and $\mathrm{W}_{3}$ according to actual investigation on site,the accurate rate about the AHP-Normal cloud model arrives at $100 \%$, it is higher than $80 \%$ of AHP-Fuzzy methods. The conclusions are drawn that it is feasible to estimate the risk level of rockfall hazards by using the normal cloud model. And the results from the AHP-Fuzzy methods agree well with those from normal cloud model and the actual Investigation on site except for sample $\mathrm{W}_{3}$ and $\mathrm{W}_{2}$ (Table 7). However, from the analysis of the monitoring values for $\mathrm{W}_{5}$ (Table 5), two indices belong to level 2, four indices belong to level 3, and two indices belong to level 4 , so it is more rational to specify $\mathrm{W}_{5}$ as level 3 than level 2 or 4 . This results 
Table 7. Assessment results of different evaluation methods about the level of rockfall hazards.

\begin{tabular}{|c|c|c|c|c|c|c|c|}
\hline \multirow{2}{*}{$\begin{array}{l}\text { Assessment } \\
\text { index }\end{array}$} & \multicolumn{4}{|c|}{ The level of rockfall hazards } & \multirow{2}{*}{$\begin{array}{l}\text { Comprehensive } \\
\text { assessment }\end{array}$} & \multirow{2}{*}{$\begin{array}{l}\text { AHP-Fuzzy } \\
\text { methods }\end{array}$} & \multirow{2}{*}{$\begin{array}{c}\text { Actual } \\
\text { investigation }\end{array}$} \\
\hline & I & II & III & IV & & & \\
\hline $\mathrm{W}_{1}$ & 0 & 0.178 & 0.364 & 0.074 & III & III & III \\
\hline $\mathrm{W}_{2}$ & 0 & 0.22 & 0.193 & 0.078 & II & III & II \\
\hline $\mathrm{W}_{3}$ & 0 & 0.178 & 0.099 & 0.074 & II & III & II \\
\hline $\mathrm{W}_{4}$ & 0 & 0.106 & 0.323 & 0.177 & III & III & III \\
\hline $\mathrm{W}_{5}$ & 0 & 0.038 & 0.559 & 0.114 & III & III & III \\
\hline $\mathrm{W}_{6}$ & 0 & 0.086 & 0.200 & 0.06 & III & III & III \\
\hline $\mathrm{W}_{7}$ & 0 & 0.142 & 0.345 & 0.107 & III & III & III \\
\hline $\mathrm{W}_{8}$ & 0 & 0.149 & 0.259 & 0.060 & III & III & III \\
\hline $\mathrm{W}_{9}$ & 0 & 0.185 & 0.414 & 0.078 & III & III & III \\
\hline $\mathrm{W}_{10}$ & 0 & 0.081 & 0.462 & 0.112 & III & III & III \\
\hline
\end{tabular}

demonstrate that the AHP-Normal cloud model is edible for predicting the risk level of rockfall hazards; According to Table 7, measured values of $U_{22}$ is closer to the classification boundary separating levels 3 and 4 for Sample $\mathrm{W}_{8}$, and measured values of $\mathrm{U}_{12}, \mathrm{U}_{13}$ and $\mathrm{U}_{32}$ are near the mean value of corresponding classification standard of level 3 (Tables 5 and 7). The classification rating according to index values of $U_{22}$ might be deterministic based on the corresponding theory, whereas the classification rating based on $\mathrm{U}_{12}$, $\mathrm{U}_{13}$ and $\mathrm{U}_{32}$ indices might be relatively uncertain when the influence of the index weight was not considered. Therefore, it was better to specify rockfall hazards of sample $\mathrm{W}_{8}$ as level 3. And it can be found in Table 7 that the certainty degrees of the scale of dangerous rock mass obtained by the normal cloud generator are $\mu_{\mathrm{I}}=0.00, \mu_{\mathrm{II}}=0.1675, \mu_{\mathrm{III}}=0.2283$ and $\mu_{\mathrm{IV}}=0.006$ for sample $\mathrm{W}_{8}$. Therefore, the certainty degree by quantitative analysis is $\mu_{\mathrm{III}}>\mu_{\mathrm{II}}>\mu_{\mathrm{IV}}>\mu_{\mathrm{I}}$, and the the scale of dangerous rock mass $\mathrm{U}_{21}$ of $\mathrm{W}_{8}$ only belongs to level III, and almost impossibly belongs to levels I, II, and IV. Furthermore, the level of dangerous rock mass $\mathrm{W}_{5}$ is more likely to be level III than that of $\mathrm{W}_{1}$, $\mathrm{W}_{4}, \mathrm{~W}_{6}, \mathrm{~W}_{7}, \mathrm{~W}_{8}, \mathrm{~W}_{9}$ and $\mathrm{W}_{10}$, because the certainty degree for level II of dangerous rock mass $\mathrm{W}_{5}(0.559)$ is higher than that of $\mathrm{W}_{1}(0.364), \mathrm{W}_{4}(0.323), \mathrm{W}_{6}(0.2)$, $\mathrm{W}_{7}(0.345), \mathrm{W}_{8}(0.259), \mathrm{W}_{9}(0.414)$ and $\mathrm{W}_{10}(0.462)$. In a word, the results based on the normal cloud model not only predict the risk level of rockfall hazards accurately, but also further determine the risk ranking of rockfall hazards for different dangerous rock mass at the same level.

\section{Conclusions}

Considering topographic and geological condition, geometry character of dangerous rock mass, as well as other factors, a new multi-index evaluation method is introduced in this paper to assess the risk level of rockfall hazards in Laoying Yan based on the AHPNormal cloud model. Required cloud drops are generated based on three numerical characteristics calculated by cloud generator algorithm. The weight coefficients of different indices were obtained by using AHP weighting method, the risk level of rockfall hazards is determined by using the comprehensive degree.

The AHP-Normal cloud model is applied to perform the risk assessment of rockfall hazards in Laoying Yan. The results indicates that the rest dangerous rock masses all belong to level III except $\mathrm{W}_{2}$ and $\mathrm{W}_{3}$ according to actual investigation on site, the accurate rate about the AHP-Normal cloud model arrives at $100 \%$, it is higher than $80 \%$ of AHP-Fuzzy methods. In other words, dangerous rock mass $\mathrm{W}_{2}$ and $\mathrm{W}_{3}$ are medium dangerous, other dangerous rock masses are high dangerous. To prevent a possible occurrence of rockfall hazards, necessible measures should be taken. In a word, not only the risk level of rockfall hazards are assessed accurately by the AHP-Normal cloud model, but also the risk ranking of rockfall hazards for different dangerous rock masses at the same level is determined. So a new method and thought is provided for the risk level assessment of rockfall hazards in the future.

\section{Acknowledgements}

This work is supported by the first batch of Natural Science Foundation of SiChuan Provincial Department of Education (no. 17ZA0270). The cross project in Nanyang Institute of Technology (230067). The National natural foundation in China (41672357). The start-up foundation (510126). Sichuan Science and Technology Program (No:2020YJ0424). 


\section{Conflicts of Interest}

The authors declare that they have no conflicts of interest.

\section{References}

1. WANG X.T., LI S.C., XU Z.H., LIN P., HU J., WANG W.Y. Analysis of Factors Influencing Floor Water Inrush in Coal Mines: A Nonlinear Fuzzy Interval Assessment Method. Mine Water Environ, 81, 38, 2019.

2. XU Z.H., WANG X.T., LI S.C., GAO B., SHI S.S., XU X.J. Parameter Optimization for the Thickness and Hydraulic Conductivity of Tunnel Lining and Grouting Rings. KSCE J. Civ. Eng, 4, 5, 2019.

3. ZHOU XIAO-PING, ZHANG JIAN-ZHI, QIAN QI-HU, NIU YONG Experimental investigation of progressive cracking processes in granite under uniaxial loading using digital imaging and AE techniques, Journal of Structural Geology, 126, 5, 2019.

4. ZHOU X.P., BI J., QIAN Q.H. Numerical Simulation of Crack Growth and Coalescence in Rock-Like Materials Containing Multiple Pre-existing Flaws. Rock Mechanics and Rock Engineering, 48, 3, 2015.

5. DONG H.G., CHEN L.D., HUANG C.S. Influence factorsand stability assessment of dangerous rocksin Yunyang-Jiangjin on three gorges reservoir [J], 18, 5, 2010.

6. LI Z., LIU Y. Single rule reasoning mapping for the two dimensional normal cloud model. CAAI Trans. Intell. Syst, $\mathbf{5}, 3,2010$.

7. WU H.N., SHEN S.L., LIAO S.M., YIN Z.Y. Longitudinal structural modelling of shield tunnels considering shearing dislocation between segmental rings. Tunn. Undergr. Sp. Tech. 33, 50, 2015.

8. WANG G.Y. The review on the unascertained information and its mathematical processing [J] Journal of Harbin Institute of Architectural Engineering, 23, 4, 1990.

9. CHIU C.L. Entropy and probability concepts in hydraulics. J. Hydraul. Eng,113, 5, 1987.

10. WANG X.T., LI S.C., XU Z.H., HU J., PAN D.D., XUE Y.G. Risk assessment of water inrush in karst tunnels excavation based on normal cloud model. Bull. Eng. Geol. Environ, 3, 9, 2019.

11. NIU Q.F., FENG Z.B., ZHANG Y.X. Susceptibility Assessment of Disaster Environment for Landslide Hazard based on GIS in Lanzhou Area [J]. Journal of Catastrophology, 32, 3, 2017. doi: 10. 3969/j. issn. $1000-$ 811X. 2017. 03. 006

12. ZHANG L., WU X., CHEN Q., SKIBNIEWSKI M.J., ZHONG J. Developing a cloud model based risk assessment methodology for tunnel-induced damage to existing pipelines. Stoch. Environ. Res. Risk Assess, 29, $5,2015$.

13. WANG L., ZHAO F., BAI C.N. Distributing Character and Risk Assessment of Geological Disasters along
Xiangyang-Chongqing Railway (Hujiaying-Wanyuan) $[\mathrm{J}]$. Journal of Catastrophology, 32, 4, 2017. doi: 10. 3969/j. issn. $1000-811 \mathrm{X}$. 2017. 04. 006.

14. WANG X.T., LI S.C., MA X.Y., XUE Y.G. Risk Assessment of Rockfall Hazards in a Tunnel Portal Section Based on Normal Cloud Model. Pol. J. Environ. Stud, 26, 6, 2017. doi:/10.15244/pjoes/68427.

15. YE S.Q., T H.M., ZHU H. Dangerous Degree Estimation of Perilous Rock Based on AHP-Fuzzy Method [J].Journal of Wuhan University of Technology, 30, 5, 2006.

16. ZHOU XIAO-PING Analysis of the localization of deformation and the complete stress-strain relation for mesoscopic heterogeneous brittle rock under dynamic uniaxial tensile loading, International Journal of Solids and Structures, 41,6,2004.

17. ZHANG JIAN-ZHI, ZHOU XIAO-PING AE event rate characteristics of flawed granite: From damage stress to ultimate failure. Geophysical Journal International, 222, 6, 2020. https://doi.org/10.1093/gji/ggaa207.

18. ELDEEN M.T. Predisaster physical planning:Integration of Disaster RISK Analysis is into physical planning-A Case Studying Tu-nisia [J]. Disasters, 4, 2, 1980.

19. MIRAUDA D., DE V.A., PANNONE M. Statistical characterization of flow field structure in evolving braided gravel beds. Spat. Stat, 34, 6, 2019.

20. LI S.C., XU Z.H., HUANG X., LIN P., ZHAO X.C., ZHANG Q.S., YANG L., ZHANG X., SUN H.F., PAN D.D. Classifification, geological identifification, hazard mode and typical case studies of hazard-causing structures for water and mud inrush in tunnels. Chin. J. Rock Mech. Eng, 37, 6, 2018.

21. MOON J., FERNANDEZ G. Effect of excavation-induced groundwater level drawdown on tunnel inflow in a jointed rock mass. Eng. Geol, $110,7,2010$.

22. LI S.C., WU J. A multi-factor comprehensive risk assessment method of karst tunnels and its engineering application. Bull. Eng. Geol. Environ, 78, 6, 2019.

23. BI J., LIU P., GAN F. Effects of the cooling treatment on the dynamic behavior of ordinary concrete exposed to high temperatures. Construction and Building Materials, 248, 3,2020 .

24. ZHAO Y., WANG C.L., BI J. Analysis of Fractured Rock Permeability Evolution Under Unloading Conditions by the Model of Elastoplastic Contact Between Rough Surfaces. Rock Mech Rock Eng, 2020, https://doi.org/10.1007/ s00603-020-02224-x.

25. XU Z.H., LI S.C., LI L.P. Risk assessment of water or mud inrush of karst tunnels based on analytic hierarchy process. Rock Soil Mech, 32, 8, 2011.

26. ZHAO Y., HE P.F, ZHANG Y.F., WANG L. A new criterion for a toughness-dominated hydraulic fracture crossing a natural frictional interface. Rock Mech Rock Eng, 52, 3 ,2019.

27. TANG H., HAN M.M., WANG L.F. Hazard Assessment of Collapsed Rock Mass in Limestone Area based on AHPFuzzy Method [J]. Journal of Catastrophology, 34, 3, 2019. 
